\title{
LA IGLESIA Y LA EDUCACIÓN EN LA CIUDAD DE MÁLAGA EN EL SIGLO XVI
}

POR

WENCESLAo SOTO ARTUÑEDo

\section{RESUMEN}

Las instituciones eclesiásticas en la educación de la población malagueña resultan especialmente importantes por el fracaso de la fundación de una universidad en la ciudad.

\section{Arstract}

The ecclesiastic institutions in the education of the population from Malaga is especially important because of the foundation's failure of the university in the city.

Para la Iglesia, educar es parte de la evangelización, en cuanto que puede disponer al sujeto para la fe; de ahí su interés en este campo, además de prestar un servicio a la sociedad. El interés de la Iglesia por fomentar instituciones educadoras abiertas a todas las capas sociales se refuerza con el decreto tridentino De reformatione, de la sesión $\mathrm{V}$ del 17 de junio de 1546 que legisla sobre las escuelas de gramática de las iglesias pobres'. En este trabajo estudiaremos la aportación de instancias eclesiales a la educación en Málaga en el siglo XVI.

' Para ura visión de conjunto ver B. BARToLOMk, «Escuelas de Gramática», en Q. ALDEA VAQUEro, T. Marín Martinez y J. Vives Gatell, Diccionario de Historia eclesiástica de España, Suplemento I, Madrid 1987, pp. 285-300. 


\section{COMPETENCIAS EN EDUCACIÓN}

En el siglo XVI la propia percepción del Estado, en cuanto a sus obligaciones sociales, era muy diversa de la actual, con frecuencia tentada de monopolio, olvidando los siglos en que otras instituciones llevaron el peso de este servicio social. En la época que estudiamos no se percibe competencia entre la Iglesia y el Estado («guerra escolar» diriamos hoy), más bien, confianza y mutua colaboración en un terreno de responsabilidad compartida, con una muy diluida delimitación de fronteras, en el que la Iglesia, con la colaboración del Estado y de los municipios, asumió el papel fundamental.

Hasta la aparición de las congregaciones de San Casiano no están claras las competencias en el terreno educativo. En las Ordenanzas Municipales de Málaga, recopiladas en 1556, no aparece función ninguna con respecto a la educación elemental por parte del Cabildo civil ${ }^{2}$, pues la instrucción básica se realizaba sin reglamentación externa y era ejercida por personas que adquirirían su cualificación profesional por la experiencia. Hasta 1520 no encontramos algún tipo de supervisión municipal, cuando dos maestros presentan unas fianzas exigidas. En 1539 existía un examen por parte del Concejo para habilitar en el ejercicio docente ${ }^{3}$.

La Iglesia ejercía una función supervisora y promotora, pues uno de los requisitos del examen referido anteriormente era, además del certificado de limpieza de sangre, el conocimiento de la doctrina cristiana, que solía acreditar el Provisor, lo que presupone un ejercicio previo de esta materia. En el caso de las escuelas de gramática sí era más clara la competencia eclesiástica, en cuanto que nombraba al catedrático, si bien el municipio no era ajeno a este ejercicio. Así el 29 de febrero de 1532 el Cabildo municipal urge al Provisor que agilice el nombramiento del catedrático de gramática, en ausencia del Obispo. Pero la financiación y gastos de mantenimiento eran fundamentalmente eclesiásticos ${ }^{4}$. La Iglesia ejercía su función especialmente a través del Maestrescuela, quinta dignidad del cabildo catedralicio, cuyas competencias incluían nombrar al maestro de gramática, a algunos de primeras letras (probablemente los clérigos) y visitar las escuelas catedralicias ${ }^{5}$. El primer Maestrescuela fue el Maestre

2 Ordenanzas de la mo noble y muy leal ciudad de Málaga, 1611, edición facsímil, Ayuntamiento Real Academia de Bellas Artes de San Telmo, Málaga 1996.

${ }^{3}$ M.' T. LóPEZ BELTRÁN, Educación, instrucción y alfabetización en la sociedad urbana malagueña a finales de la edad media y principios de la edad moderna, Universidad de Málaga, 1997, pp. 3170.

4 (A)rchivo (C)abildo (C)atedral (M)álaga, (AA. CC.) Actas Capitulares, vol 14 (1589-1598), fol. 39: cabildo 01.12.1589.

5 V. González SANCHEz, Málaga: perfiles de su historia en documentos del Archivo Catedral (1487-1516), Imprenta Atenea, Málaga 1994, 455.

Actas del 1 Congreso de Historia de la lglesia y el Mundo Hispánico

Hispania Sacra, 52 (2000) 
Rodrigo Martínez de Enciso, nombrado en abril de $1488^{6}$. De 1504 y, al menos, hasta 1510 lo era Francisco de Melgar?. El 15 de marzo de 1553 la vacante dejada por Fernando de Córdoba es ocupada por Constantino de Carvajal ${ }^{8}$, quien continuaba en ella en $1595^{\circ}$. Las potestades del Maestrescuela se mantuvieron hasta que por constituciones aprobadas por el Real Consejo el 18 de septiembre de 1730 , las funciones asignadas hasta entonces a esta dignidad dejaron de ser privativas de ella ${ }^{10}$.

Vamos a recorrer las distintas etapas educativas, utilizando anacrónicamente los términos actuales.

\section{ENSEÑANZA ELEMENTAL}

Guillén Robles nos ofrece una visión optimista de la oferta educativa de Málaga tras la reconquista en 1487, al indicar que los Reyes Católicos crearon escuelas dotadas de maestros conocedores del árabe para impartir las primeras letras y castellano a los musulmanes ${ }^{13}$.

La enseffanza elemental se circunscribía a la lectura, escritura y unos fundamentos de matemáticas y se impartía fundamentalmente en centros de iniciativa privada, por los conocidos como «maestros de enseñar moços a leer y escrevir», "maestros de bezar moços» o «maestro de mostrar mozos», que solían alternar este oficio con otro. Algunos de los primeros repobladores lo eran, como Juan de Contreras, Benito Martínez, Alonso de la Barrera, López Sánchez de Torralva, Alonso Allende, etc. Socialmente estaban equiparados a los libreros y otros artesanos como pintores, tintoreros, jaboneros, horneros de bizcocho y «de pan cozer» etc., ya que éste era el lugar que se les asigna en la procesión del Corpus $^{12}$. En 1539 hubo un total de 28 maestros ${ }^{13}$, que se redujeron a 6 en 1559,4 de ellos en el sector de las parroquias de El Sagrario y Santiago; además conta-

\footnotetext{
${ }^{6}$ V. GonZÁLEZ SANCHEZ, «En torno a un centenario. Artifices de la «Institución» de la Iglesia de Málaga. 1487-1987\%, en prensa, pp. 71-72.

7 ACCM, AA. CC., vol 2 (1504-1510), fol. 1: cabildo 05.01.1504.

8 ACCM, AA.CC. leg. 1026, 1, (1550-1554) fol. 138v

${ }^{9}$ ACCM, AA.CC., Leg. 1026, 2 (1555-1562), fol. 1; Leg. 1027, 1 (1572-1579), fol. 1.

${ }^{10}$ (A)rchivo (M)unicipal (M)álaga, Originales, vol. 48, ff. 153 ss.: RC de Felipe V, Sevilla 24 de junio de 1731, respondiendo a la protesta del maestrescuela Francisco del Castillo Ventimilla,

1 F. GUllı́́ RoBles, Málaga musulmana. 2 Tomos, 1880, edición facsímil Arguval 1984, vol. 11, pp. 619-620.

12 Regulación hecha el 13 de junio de 1498, Ordenanzas de la muy noble y muy leal ciudad de Málaga, p. 144.

${ }^{13}$ M." T. LÓPEZ BELTRAN, op. cit., pp. 31-70.
}

Actas del I Congreso de Historia de la Iglesia y el Mundo Hispánico Hispania Sacra, 52 (2000) 
ba la ciudad con un maestro de esgrima y otro de música ${ }^{14}$. Los nombres de dos de estos maestros eran Diego González de Aguilar y Andrés Beltrán, y en 1562 están identificados como tales Alonso de Moriana y Cristóbal Merino, quien, además, era especiero ${ }^{15}$. En los libros de repartimientos se mencionan los lugares de enseñanza como «escuela de bezar mozos a leer», "Casa escuela», «las tiendas de la escuela» «tienda e mezquita que hera escuela».

El proceso se adscripción de los pupilos comenzaba con la formalización de un contrato entre el padre del alumno y el maestro ante escribano público, mediante el cual el docente se comprometía a enseñarle al discípulo a leer, escribir y contar, al menos, y en algunos casos en régimen de internado. Como pago por su trabajo, recibía un salario de 120 maravedís anuales en 1496, que en 1538 había ascendido a 780 . A veces se utilizaban otras fórmulas contractuales, como intercambiar servicios del alumno por la ensefianza ${ }^{16}$.

La Iglesia puso en marcha entidades como la catequesis-escuela o escuela parroquial. Aunque su objetivo era el catecismo, parece que se trataba de una escuela aneja a las parroquia a cargo del párroco o del sacristán ${ }^{17}$. Especial interés tenía la Iglesia en formar «profesionalmente» a sus jóvenes servidores para que cumplieran mejor su oficio; así en los estatutos de 1492 de la Iglesia de Málaga se establece la obligatoriedad de enseñar a los niños de coro ${ }^{18}$, y cien años más tarde se establece que esta obligación recayese sobre el maestro de capilla $^{19}$. Por otro lado, el 1 de marzo de 1563 se acordó hacer una casa de muchachos de Doctrina ${ }^{20}$.

También el municipio promovió, o lo intentó, al menos, este nivel educativo. En 1572 hay en Málaga un personaje llamado Juan Juviel, que enseñaba la doctrina cristiana y a leer, a escribir y otras buenas costumbres, a los niños pobres ${ }^{21}$.

${ }^{14}$ M. T. López Beltrán y S. Villas Tínoco, «Un censo malaguef́o de 1559», Baetica, 3 (1980), pp. 143-153.

15 V. GonZALEZ SÁNCHEZ, Caracteres de la sociedad malagueña en el siglo XVI, Diputación Provincial de Málaga, 1986, pp. 46-49.

${ }^{16}$ M. T. T. LÓpez BeLtrán, op. cil., 10-14.

17 B. Bartolomé Martinez, "Las escuelas de primeras letras", en B. BarTolomé MarTiNeZ (Dir.), Historia de la acción educadora de la Iglesia en España. I: Edades antigua, media y moderna, BAC, Madrid 1995, pp. 612-630, especialmente pp. 614-616.

18 Estatutos de la Catedral de Málaga, Málaga, 1907, p. 24.

I9 ACCM, AA. CC., 02.10.1592

20 C. Garcta de la LeÑa (C. MEdna CONDE), Comversaciones históricas malaguefias, 4 tomos, 1787, edición facsímil de la Caja de Ahorros Provincial de Málaga, 1981, Tomo III, p. 219.

${ }^{21}$ En el margen de la página correspondiente del libro de actas capitulares se añadió uteatino», término que en el acta del 7 de agosto de 1570 se utiliza para designar a los jesuitas (AMM, AA. CC., vol. 19 (1569-1571), fol. 123). Aunque es probable que ya hubiera en la ciudad algún jesuita preparando la casa donde residirian, no parece que se refiera a ninguno de ellos.

Actas del I Congreso de Historia de la Iglesia y el Mundo Hispánico

Hispania Sacra, 52 (2000) 
La ciudad acordó escribir al regidor Diego de Torres, entonces en la corte, para solicitar permiso a fin de asignarle fondos con que pagar una casa, «ya que tiene de limosna más de quince muchachos e los tiene y les da buenas costumbres; lo qual se haga porque es provechoso a la ciudad ${ }^{22}$. Suponemos que en relación con esta solicitud, por Real Despacho firmado en Madrid el 23 de mayo de 1572 se relaciona la pretensión de la ciudad de que se le diese licencia para satisfacer de sus propios 12.000 maravedís anuales de salario para un maestro que enseñara a leer, escribir y contar a los hijos de la ciudad, y se pide información sobre el tema ${ }^{23}$.

En 1573 se inicia una institución benéfica en la que suponemos que se enseñaban también las primeras letras: la casa de Niffos Expósitos. Medina Conde la vincula con el gremio de carpinteros que, para atender a los niffos, pagaban a una mujer con los réditos de algunos censos, además de otras dádivas que un limosnero recogia por la ciudad ${ }^{24}$. Villena Jurado identifica esta institución con el hospital de convalecientes ${ }^{25}$, del que dice que acogía a nifios expósitos desde 1573 hasta 1645, y estaba situado en las casas de Juan Ximénez de Avila ${ }^{26}$.

\section{ENSENAanzas MEDIAS}

Las Escuelas de Gramática ${ }^{27}$ hacían la función que realizan actualmente los centros de enseñanza media, como preparación para carreras eclesiásticas o burocráticas, $o$ iniciar estudios universitarios. Además de las cátedras de gramática, había otro modo de iniciarse en el latín, pagando a clérigos de la ciudad como preceptores particulares ${ }^{28}$, cuya presencia en Málaga consta desde su incorporación a Castilla, como Alonso de Segura, que poseía una casa en la calle Beatas ${ }^{29}$ y Gonzalo Tenorio, en $1512^{30}$. En los Repartimientos se cita una casa de Gramática en una barrera de la calle Granada, que debió resultar insufi-

\footnotetext{
${ }^{22}$ AMM, AA. CC., vol. 20 (1569-1573), fol. 132: cabildo de 30.04.1572.

${ }^{23}$ AMM, Originales 7, ff. 87-92.

${ }^{24}$ B. Bartolomé MARTINEZ, «Los centros de asistencia, corrección y formación de minorías sociales en la iglesia moderna españolay, en B. BARToLomÉ MARTINEZ, op. cit., pp. 971-974; C. GARCfA DE LA LENAA, op. cit., IV, pp. 132-135.

${ }^{25}$ C. Garcia de LA LeNA, op. cit., Tomo IV, pp. 12-13.

26 J. VILLENA JURADO, Málaga en los albores del siglo XVII desde la documentación municipal (1598-1605), Diputación Provincial, Málaga, 1994, pp. 123, 127.

${ }^{27}$ B. Bartolomé MartfNeZ, uLas escuelas de Gramática», en B. BarTolomé MarTíneZ, op. cit, pp. 631-644, especialmente 639 .

${ }^{28}$ M.' T. LÓPEZ BeLtrÁn, op. cit., pp. 14-22.

29 ACCM, AA. CC. vol. 2 (1504-1510), fol. 60: cabildo 04.07.1509.

30 V. GONZALEZ SANCHEZ, op. cit. 1986, pp. 46-49.
} 
ciente ya que en 1522 se solicita al Cabildo un solar para estudio de gramática ${ }^{31}$.

Al final del siglo XVI el obispo García de Haro $^{32}$ (1587-1597) resume la situación de su diócesis en cuanto a la enseñanza, en la visita «ad limina» de 1589:

«Nella città di Malaga, et nell'altre del vescovato ci sono schole et cathedre di Latinitá dove s'insegnano con sollicitudine li putti nella virtú, et nelli principis delle lettere, et anco nella detta cittá di Malaga ci é un Collegio della Compagnia di Jesú, dove s'insegna latino di modo che non ci è bisogno di Seminarion ${ }^{33}$.

\subsection{El Estudio de Gramática de Málaga}

En la parroquia de Santa Maria, se adjudicó un mesón para estudio de gramática el 2 de marzo de 1493, y aunque esta casa había sido entregada antes al noble Alonso de Córdoba, señor de Zuheros, «queda proveyda a la cibdad para escuela de gramatica $)^{34}$. Según Bolea y Sintas se utilizaron como casas de cabildo y en febrero de 1553 fueron compradas a la Ciudad para el solar que ocuparía la nueva iglesia catedral ${ }^{35}$. Parece, pues, que este estudio de gramática, no prosperó. Puede ser el mismo "estudio de esta çibdad) ${ }^{36}$, situado en la calle del Alcázar (Cister), y lindero con casas de Juan Hurtado ${ }^{37}$, que aún existía en $1547^{38}$.

Posteriormente, el estudio de gramática se estableció en el hospital de Santo Tomé, del que era copatrón el Cabildo eclesiástico, por acuerdo del cabildo de 11 de abril de 1524, y después pasó a la claustra de la catedral, hasta que su dotación se incorporó al seminario a principios del XVII, y use hizo en él una sala para poner dicha catedra de Gramática por que los Colegiales tuviesen pronta enserianza» ${ }^{39}$.

${ }^{31}$ M. ${ }^{2}$ D. AgUlar García, Málaga: (1487-1550) Arquitectura y ciudad, Diputación Provincial, Málaga 1998, p. 248.

32 F. MondéJAr Cumpián, Obispos de la Iglesia de Málaga, Cajasur, Córdoba 1998, pp. 205-208.

${ }^{33}$ Archivum Secretum Vaticanum, S. Congr. Concilii Relationes. Malacitan Caja 482 A, fol. 125. Igual contenido en la de 1594 (fol. 326v).

${ }^{34}$ ACCM, Libro $3^{\circ}$ de los Repartimientos, fol. 28, transcripción de F. Bejarano Robles, Los Repartimientos de Málaga II. Ayuntamiento, Málaga 1990, p. 53.

${ }^{35}$ M. BolEA Y SINTAS, Descripción histórica de la catedral de Málaga, Málaga 1894, p. 156.

${ }^{36}$ ACCM, AA. CC. vol. 2 (1504-1510), fol. 51v: cabildo 12.09.1508.

${ }^{37}$ ACCM, AA. CC. vol. 2 (1504-1510), fol. 38: cabildo 21.04.1507; fol. 41: cabildo 26.10.1506.

${ }^{38}$ M.' D. Agullar Garcia, Malaga: (1487-1550) Arquitectura y ciudad, Diputación Provincial, Málaga 1998, p. 249.

${ }^{39}$ ACCM, AA. CC., 43 (1723-1727), 101-102: 19.07.1723.

Actas del I Congreso de Historia de la Iglesia y el Mundo Hispánico Hispania Sacra, $52(2000)$ 
En el estatuto de la Iglesia de Málaga de Don Pedro de Toledo (1488-1499), se le asigna al catedrático de gramática una fanega de trigo, o su valor donde no hubiera trigo, en cada pila bautismal del obispado, tanto de cristianos nuevos como viejos, más otra fanega por todos los anejos. Pero él mismo tenía que preocuparse de recorrer los pueblos para recoger su salario. Es la misma paga que se mantenía por los colegiales en $1748^{40}$, más las cuotas de otros alumnos particulares. En 1524 se llega a un acuerdo con el preceptor, el bachiller Juan Rodríguez, para que enseñe gratis a determinados ('mozos de Iglesia" y beneficiados, a cambio de darle todas las fanegas de trigo en un mismo lugar, que solía ser La Hoya, Almogía o Antequera ${ }^{41}$. Esta concesión se repetía anualmente, durante el verano, previa solicitud por parte del interesado. Así, el catedrático Juan de Valencia solicita en 1555 , se le conceda su salario en un mismo sitio o que se traiga a Málaga junto con la parte del cabildo, a lo que se accede, incluyendo desde entonces el pan del catedrático dentro de los propios cobros decimales del cabildo, pagando el interesado los gastos de transporte ${ }^{42}$, pero en los lugares donde no lo traía el cabildo se debía encargar él de cobrarlo ${ }^{43}$.

Parece que la Ciudad, consciente del beneficio social de la enseñanza de Gramática, hizo instancia al Emperador, en 1538, sobre la utilidad de un estudio de gramática, regido por un maestro al que se le asignarian 10.000 maravedís al afio, a cargo de sus propios y rentas. Carlos $V$ pidió informes sobre esta solicitud, $\mathrm{y}$ al final de af́o aprobó dar un salario de 10.000 maravedís, además del pan que se les solía dar por la dotación de la cátedra ${ }^{44}$. Por este último dato suponemos que no se trata de crear otra institución, sino de reforzar la que ya existía.

Los alumnos eran los mozo de coro y prebendados jóvenes (capellanes y racioneros), si bien «los beneficiados estudiantes no ganaban maitines» ${ }^{45}$, salvo

\footnotetext{
40 (A)rchivo (H)istórico (N)acional, Consejos, 13.119, citado por F. VENTAJAS Dote, «Alfabetización y educación en la Málaga preilustrada. La ensefianza de primeras letras durante el reinado del Fernando VI (1746-1759). Tesis de Licenciaturas. Departamento de Historia Modema y Contemporánea, Universidad de Málaga, 1999, 130.

41 ACCM, AA. CC., Leg. 1024, 2, fol. 101v: cabildo 09.01.1524; fol. 111: cabildo 05.03.1524; fol. $159 \mathrm{v}$ : cabildo 29.11 .1525 .

${ }^{42}$ ACCM, AA. CC. Leg. 1024 (1555-1561), fol. 59, cabildo 15.06.1555. Juan de Valencia io solicita en 1557, ACCM, AA.CC. Leg. 1024 (1555 - 1561), fol. 58v: cabildo de 23.06.1557; fol. 109v: cabildo de 27.07.1558; fol. 191: cabildo 16.08.1561. El catedrático bachiller Juan de Cárdenas lo solicitó, y se le concedió, el 31 de agosto de 1568, y en otras ocasiones, ACCM, AA. CC, Leg. 1026, 3, fol. 277 (1562-1571); fol. 310; fol. 341v.: 26.07.1570; Leg. 1027, 1 (1572-1579), fol. 23, cabildo del 23.08.1572.

${ }^{43}$ ACCM, AA. CC, Leg. 1026, 3, (1562-1571), ff. 391v-392: cabildo 06.07.1571.

44 AMM, Originales, vol. 6, ff. 96-102: RC de Carlos V, Valladolid 19 junio 1538; AMM, Originales, vol, 6, ff. 107-109: RC, Toledo 10.12.1538.

45 ACMM., AA. CC., Leg. 1024, 2, fol. 117v: cabildo 27.05.1524.
} 
que les concedieran las horas de la mañana para dedicarse al estudio, lo que ocurría con frecuencia, a pesar de determinados abusos. Otros discípulos eran los criados de dignidades y los hijos de la nobleza y oligarquía locales. En 1524 se manda al preceptor de gramática que debía enseñar a seis mozos de iglesia, más uno de cada beneficiado ${ }^{46}$. En 1536 tenía hasta 80 estudiantes, que en 1548 llegaron al centenar, regidos por un maestro y un repetidor.

Varias son las alusiones al catedrático de gramática de las que disponemos: El 29 de febrero de 1532 se acordó urgir el nombramiento para la cátedra de Gramática. De 1525 a 1530 el preceptor de Gramática era el bachiller Juan Rodríguez. En 1539 se celebraron oposiciones en la capilla de Santa Bárbara. En 1547 y 1548 el preceptor era el bachiller Diego de Valencia y el repetidor, Bernardo de Castro. Gonzalo Fernández Negrón había sido catedrático en Ronda y fue llamado para ejercer en Málaga, en $1589^{47}$.

\section{Fundación del seminario diocesano}

Además de la cátedra de Gramática anterior, se fundó la del seminario diocesano. Inició el proceso el obispo García de Haro en 1587, sufriendo la oposición del Cabildo que quería un colegio de mozos de coro y altar. El 8 de octubre de 1597 el príncipe Carlos, en nombre de Felipe II expide la Real Cédula de erección del colegio-seminario, indicando que debía cumplir ambas funciones. Lo inició Don Tomás de Borja Castro-Pinós ${ }^{48}(1600-1603)$ en 1600. En las constituciones de 1604 ya aparece la enseñanza de latín, lo que suponía la existencia de cátedra de Gramática, a la que se unieron otras enseñanzas ${ }^{49}$. Aunque desde el principio acudían alumnos no seminaristas, en 1755 se admite libremente a cuántos malagueños quisieran acudir a sus aulas, sin perspectiva de estudios sacerdotales.

\section{El colegio de la Compañia de Jesús}

Uno de los instrumentos más generalizados para la educación secundaria fueron los colegios de los jesuitas, que suplieron la escasez de las escuelas de

46 AMM, AA.CC. vol. 6(1518-1528), fol. 101 v: cabildo de 13.01.1524.

47 C. MEssa Poullet, La música en la catedral de Málaga durante el renacimiento, Tesis doctoral inédita, Universidad de Granada, Departamento de Historia del Arte, 1997, vol. I, pp. 287-288.

48 Ibid, pp. 209-213.

49 M. DEL VAlLe ZAmudio, Apuntes históricos del Seminario de Málaga, Málaga 1928, edición facsímil Málaga 1985; J. J. Bravo CARo, «El primer intento de regular el Colegio Seminario de Málagan, Baetica 18 (1996), 349-358; F. ARANDA OTERo, Seminario de Malaga, 1597-1997: 400 años de historia. Lección inaugural del Curso 1997-1998, Seminario diocesano, Málaga, 1997.

Actas del I Congreso de Historia de la Iglesia y el Mundo Hispánico

Hispania Sacra, 52 (2000) 
gramática. Su éxito se debió a su gratuidad, al orden y método establecido en el caos de las enseñanzas secundarias, y a la educación moral y religiosa imparti$\mathrm{da}^{50}$. Guillén Robles presenta la llegada de los jesuitas a Málaga:

«Las autoridades eclesiásticas, civiles o particulares mantuvieron escuelas donde se ensef́aban las primeras letras a los niños y la doctrina cristiana, que en determinados dias recitaban salmodiando en calles y plazas. Se aumenta con la Compañía de Jesús que se dedicó a propagar entre la juventud el amor a las letras del Lacio y el conocimiento de la Historia y Literatura patrias $\$ 1$.

En 1568 comenzaron los jesuitas la actividad apostólica en estas tierras, celebrando misiones populares en Málaga, Antequera, Archidona y Ronda. Esta presencia fue alentada por el obispo Don Francisco Blanco Salcedo ${ }^{52}$ (15651574), fervoroso amigo de la Compañía desde que ocupó la mitra de Orense y más aún cuando coincidió en Trento con los más ilustres teólogos ignacianos, y comenzó a planificar la fundación de un colegio ${ }^{53}$.

En la diócesis de Málaga hubo dos colegios, uno en la capital y otro en Antequera, y se intentó un tercero en Vélez-Málaga, que no llegó a fraguar. Desde la apertura del colegio de Málaga en 1572 los jesuitas irían tomando el protagonismo en la ensefianza secundaria, siendo durante la mayor parte de la Edad Moderna el único centro público de enseñanza de gramática. Se aplicaba la Ratio Studiorum, el plan de estudios propio de los jesuitas, a través del cual los estudiantes recibían una formación integral, de conocimientos, habilidades y valores, es decir, se educaba en «virtud y letras». Los alumnos tenían frecuentes actos de piedad, salían a las calles a proclamar la doctrina cristiana en las procesiones de doctrina, y acompañaban a los jesuitas en algunos ministerios, como visitas a hospitales.

El obispo solicita oficialmente la fundación del colegio de Málaga al $P$. General Francisco de Borja el 21 de agosto de $1570^{54}$. Tras la aceptación, les compra unas casas y consigue que Felipe II les conceda la ermita y el hospital de San Sebastián, contiguos a las casas. Así se funda el colegio en 1572, con el

${ }^{50}$ A. Mestre, «Marco histórico: Iglesia, Sociedad y Educación», en B. BARTolómE MARTínEZ, op. cit., pp. 461-485.

${ }_{51}$ F. Gullén RoBles, Historia de Málaga y su provincia, 2 Tomos, 1874, edición facsímil de Arguval, Málaga, 1985, p. 620.

${ }_{52}$ F. MONDÉJAR CUMPIÁN, op. cit., pp. 185-199.

${ }^{53}$ (A)rchivum (R)omanum (S)ocietatis (D)esu, Baetica. 22, fol. 85: Fundación y progreso del colegio de la Compañia de Jesús de Málaga.

${ }_{54}$ ARSI, Eppistolae Externorum, 12, 36-37, publicada en Monmenta Historica Societatis lesu, Sanctus Franciscus Borgia, quartus Gandiae dux et Societatis lesu Praepositus tertius, 5 vol. Madrid 1894-1911, V, pp. 476-478. 
nombre de San Sebastián, por el titular que los Reyes Católicos habían dado a la ermita, que era una antigua mezquita. Para consolidar la fundación del colegio se compró un cortijo en Campo de Cámara con un donativo que dio el fundador, siendo ya Arzobispo de Santiago. También se aplicó al colegio la huerta del Pilarejo o Santa María de los Angeles, llamada después Teatinos, al no ser aceptada por los franciscanos para fundar un convento, según dispuso en su testamento su propietario, Don Fernando de Puebla, arcediano de Málaga ${ }^{55}$.

El Rector Baltasar de Santofimia llegó en 1578 y determinó poner «escuelas donde la juventud se crie en virtud y letras" ${ }^{56}$. Lo comunicó al obispo Don Francisco Pacheco de Córdoba ${ }^{57}$ (1575-1587) que también quería esas escuelas, pero no había espacio ni comodidad para ello. Consiguió que Don Francisco Blanco, ya Arzobispo de Santiago, aplicara los 4.000 ducados que había dejado para la fundación del hospital de convalecientes, ya que no fueron aceptados por los herederos de Doña Isabel Dalvo. El obispo Pacheco dio también una limosna de 600 ducados, que completó la suma necesaria para adquirir una casa colindante a la de los jesuitas, $y$ acomodarla como escuela ${ }^{58}$.

El Ayuntamiento también contribuyó a la consolidación del colegio, el 27 de Junio de 1576, con su acuerdo de ceder la ermita de Santa Lucía para poder empezar la enseñanza, y prometiendo 1.000 ducados que daría posteriormente. Por el año de 1578 se estaban acomodando los locales para 263 clases de gramática según «acudiesen los estudiantes», comenzando las clases en $1579^{59}$.

Acudían a estas aulas «todos los hijos de esta Ciudad y su comarca», argumento utilizado para pedir la donación de agua al Ayuntamiento, ya que la que bebían era de un pozo que no ofrecía todas las garantías ${ }^{60}$. En la respuesta de la Ciudad, en enero de 1580, se subraya la utilidad social del colegio, donde se enseñaba gratis:

ss Institutum Historicum Societatis Iesu, Roma, Ms. «Historia del Colegio de la Companía de Jesús de Málaga. Tomo primero. Tiene setenta capítulos y sesenta y dos PP. Rectores, de los cuales el primero es el P. Cristóbal Méndez Lobo y el último el P. Antonio Franquís. Contiene este tomo los hechos desde el año 1572 hasta mediado el año de 1759 m.

56 «Historia del colegio...", pp. 8.

57 F. MONDÉJAR CUMPEÁ, op. cit., pp. 201-204.

58 Archivo Histórico Provincia Bética S.J., Granada: Martín DE ROA, Historia de la Compañia de Jesús de la Provincia de Andalucía, copia manuscrita del siglo XIX, del original de la Biblioteca de la Universidad de Sevilla, fol. 27.

59 (Historia del colegio...", p. 90.

60. (A)rchivo (D)iocesano (M)álaga Documentos del Acueducto de San Telmo, Leg. 36, 1, fol. 4 : Petición del rector Baltasar de Santofimia en 1579, Testimonio del expediente y títulos de la propiedad de las aguas del colexio, desde el affo de 1580, copia del escribano público Schumaquer, Málaga, 3 de noviembre 1820 .

Actas del I Congreso de Historia de la Iglesia y el Mundo Hispánico Hispania Sacra, $52(2000)$ 
«considerando el beneficio que esta dicha Ciudad resive, ansí en la buena doctrina que alli aprenden los hijos de los Becinos de esta Ciudad, y atento que en la dicha Casa y Colegio donde se enseña la Latinidad sin ningún interés a todos los hijos de besinos de esta Ciudad e por ser el beneficio tan común $[\ldots]^{61}{ }^{61}$.

Después de un primer periodo floreciente, entró en crisis, no llegando a 70 estudiantes en 1585 , y además en un convento querían poner escuelas públicas $^{62}$. Continuó la crisis a pesar de que se pusieron otros maestros, a juicio del rector Ignacio del Castillo, por la competencia de la cátedra del cabildo, puesto que la mayoría de los ciudadanos preferían ir allí, al exigírseles menos esfuerzo. Por esto el rector propuso que se cerraran las escuelas de gramática ${ }^{63}$. En este mismo rectorado se superó la crisis, y no sólo continuaron las clases de latinidad, sino que después, a lo largo de los siglos XVII y XVIII se afiadieron otras enserianzas: teología moral, filosofía, teología escolástica y clases para leer y escribir. Incluso durante algún tiempo estudiaron aqứ los jóvenes jesuitas.

El colegio era una plataforma apostólica, que cumplía una función de educación social. Entre ellas la predicación ocupaba un lugar preferente, tanto en la iglesia como en la Puerta del Mar. También realizaron muchas misiones o predicaciones rurales por toda la provincia y otras partes como Melilla. Además de las actividades directamente pastorales, ejercitaban actos humanitarios, como pacificar a desavenidos, asistir a las víctimas de las muchas calamidades (peste, terremotos, inundaciones, etc.) que sufrió la ciudad de Málaga en la Edad Moderna, pereciendo algunos jesuitas en el desarrollo de esta tarea. Cabe destacar la atención espiritual y material a los presos de la entonces cercana cárcel. Para ello fundaron en 1593 la Real Congregación de San Juan Bautista en su Degollación, para alimentar y vestir a los presos pobres.

\section{Estudios Universitarios}

El frustrado proyecto de una Universidad en Málaga aparece vinculado a la Iglesia, en relación con el mayorazgo fundado en 1561 por el regidor Juan de Berlanga Maldonado, poniendo como condición que al extinguirse su descendencia masculina se fundara una universidad en sus casas. Su Visitador debía ser el Sr. Obispo y el prior de Santo Domingo, y sus patronos el deán y cabildo de la catedral y los superiores de los conventos de Santo Domingo, San Francisco, Santísima Trinidad, Merced y la Victoria. Se pondrían las cátedras de Gra-

61 Ibid, fol. 4v.

62 ARSI, Hispania, 131, ff. 105 v-106: Gil González a Aquaviva, Córdoba 30.12.1585.

${ }^{63}$ ARSI, Hispania, 137, fol. 329: Cristobal Méndez a Aquaviva, Trigueros 24.11.1594. 
mática Latina, Gramática Griega, Retórica, Arte, Teología, Derecho y Medicina con el título de «Colegio del Sr. San Agustín». A mediados del siglo XVII se presentó la circunstancia prevista en la fundación del mayorazgo de extinción de la sucesión masculina, pero no se llevó a cabo este deseo de equiparar a Málaga con la vida universitaria de Granada, Baeza y Osuna. Igual ocurrió con otra ocasión sucedida en $1713^{64}$.

A falta de universidad, en casi todos los conventos había enseñanza de teología y filosofia, fundamentalmente para sus frailes. Uno de esos colegios-convento, era el de los dominicos, que en el siglo XVII fue elevado a la categoría de Estudios Generales ${ }^{65}$. En 1602 los dominicos piden al Cabildo municipal una limosna para abrir unas aulas en su convento, pero el Concejo no lo concedió, decidiendo apoyar incondicionalmente al colegio seminario, entonces de un nivel académico superior ${ }^{66}$.

64 Garcja de La LeNA, op. cit. Tomo IV, 234; M. Reder GaDow, «La frustración de un desideratum: La fundación universitaria de D. Juan de Berlanga en Málaga (1561)», Baetica (1989), pp. 240250; M. REDER GADOw, «La fundación de la universidad de Málaga o la utopía del regidor Juan Berlanga», en Universidade(s), História, Memória, perspectivas. Actas do Congresso «História da Universidade" (No $7^{\circ}$ Centenário da sua Fundaçâ), 5 al 9 de Março de 1990, Coimbra 1991, pp. 8399; M. ReDER GADow, «El proyecto renacentista de la Universidad de Málaga (1561)», Péndulo, 5 (1993) pp. 33-40.

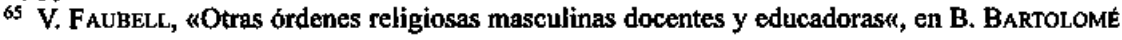
MARTINAZ, op. cit., pp. 709-722, especialmente 719.

66 J. VILlena JURADO, op. cit., p. 142.

Actas del I Congreso de Historia de la Iglesia y el Mundo Hispánico Hispania Sacra, 52 (2000) 